OPEN ACCESS

Edited by:

Erdinc Sezgin,

Karolinska Institutet (KI), Sweden

Reviewed by:

Turan Demircan,

Muğla University, Turkey Vitezslav Bryja,

Masaryk University, Czechia

${ }^{*}$ Correspondence:

De-LiSh

de-li.shi@upmc.fr

Specialty section:

This article was submitted to

Signaling,

a section of the journal

Frontiers in Cell and Developmental

Biology

Received: 28 July 2020 Accepted: 15 September 2020 Published: 30 September 2020

Citation:

Shi DL (2020) Decoding Dishevelled-Mediated Wnt Signaling in Vertebrate Early Development. Front. Cell Dev. Biol. 8:588370. doi: $10.3389 /$ fcell.2020.588370

\section{Decoding Dishevelled-Mediated Wnt Signaling in Vertebrate Early Development}

\author{
De-Li Shi* \\ Developmental Biology Laboratory, CNRS-UMR 7622, IBPS, Sorbonne University, Paris, France
}

Dishevelled proteins are key players of Wnt signaling pathways. They transduce Wnt signals and perform cellular functions through distinct conserved domains. Due to the presence of multiple paralogs, the abundant accumulation of maternal transcripts, and the activation of distinct Wnt pathways, their regulatory roles during vertebrate early development and the mechanism by which they dictate the pathway specificity have been enigmatic and attracted much attention in the past decades. Extensive studies in different animal models have provided significant insights into the structure-function relationship of conserved Dishevelled domains in Wnt signaling and the implications of Dishevelled isoforms in early developmental processes. Notably, intra- and intermolecular interactions and Dishevelled dosage may be important in modulating the specificity of Wnt signaling. There are also distinct and redundant functions among Dishevelled isoforms in development and disease, which may result from differential spatiotemporal expression patterns and biochemical properties and post-translational modifications. This review presents the advances and perspectives in understanding Dishevelled-mediated Wnt signaling during gastrulation and neurulation in vertebrate early embryos.

Keywords: Wnt signaling, Dishevelled, Wnt/B-catenin, Wnt/PCP, convergence and extension, mouse, Xenopus, zebrafish

\section{INTRODUCTION}

Wnt signaling plays critical roles in a wide variety of biological processes, including embryonic axis formation, cell proliferation, differentiation and migration, polarity establishment, and stem cell self-renewal (Steinhart and Angers, 2018; Wiese et al., 2018). Upon stimulation by Wnt ligands, membrane receptors (Frizzled) and co-receptors (LRP5/6, glypican-3/4, ROR, and RYK) assemble into complexes to activate divergent pathways (Niehrs, 2012; Green et al., 2014; Stricker et al., 2017). The activity of Frizzled receptors is further controlled by an auxiliary regulatory system involving RSPO1-4, LGR4/5/6 and ZNRF3/RNF43 (Jiang and Cong, 2016; Lehoczky and Tabin, 2018). The canonical Wnt pathway (Wnt/B-catenin) regulates target gene transcription through stabilization and nuclear accumulation of $\beta$-catenin by inhibition of its destruction complex, consisting of AxinGSK3ß-APC, whereas the non-canonical Wnt pathway (Wnt/planar cell polarity or Wnt/PCP) is implicated in polarized cellular orientation and asymmetric cell movements through activation of major regulators of the cytoskeleton. Aberrant signaling of both pathways leads to tumorigenesis and metastasis of multiple cancer types, as well as human birth defects (Clevers and Nusse, 2012; 
Butler and Wallingford, 2017; Humphries and Mlodzik, 2018), but how they are regulated in development and disease remains elusive.

Dishevelled (Dvl or Dsh in Drosophila) is a family of proteins that function as common intracellular conductors of both Wnt/ß-catenin and Wnt/PCP pathways (Boutros and Mlodzik, 1999; Wallingford and Habas, 2005; Gao and Chen, 2010). Drosophila $d s h$ alleles were first identified in genetic mutants with disruptions of hair and bristle polarity (Wallingford and Habas, 2005). Vertebrates possess three highly conserved $D v l$ genes. Extensive studies in mouse, Xenopus and zebrafish have revealed their critical roles in germ layer specification and morphogenetic movements, which require Wnt/ß-catenin and Wnt/PCP signaling, respectively. There is accumulating evidence that Dvl isoforms display both distinct and redundant functions (Gentzel and Schambony, 2017). However, a number of important questions regarding Dvl-mediated Wnt signaling during development remain enigmatic (Mlodzik, 2016), such as Dvl-regulated switch of distinct Wnt pathways, the specific functions of Dvl isoforms in Wnt signaling and development, the post-translational modifications of Dvl functions, and the maternal contributions of Dvl to early developmental events. Fortunately, structure-function and mutational analyses have significantly advanced our understanding of Dvl-regulated Wnt signaling in development and disease. This review focuses on progresses made in this fascinating research field by using complementary vertebrate animal models.

\section{DvI FUNCTIONAL DOMAINS IN Wnt SIGNALING}

Dvl proteins contain several highly conserved domains required for activating different Wnt pathways, including in particular the N-terminal DIX (Dishevelled and aXin) domain, the central PDZ (Post-synaptic density protein-95, Disk large tumor suppressor, Zonula occludens-1) domain, and the C-terminal DEP (Dishevelled, Egl-10 and Pleckstrin) domain (Figure 1). The DIX domain is involved in Wnt-induced dynamic Dvl homoand hetero-oligomerization that is important for $\mathrm{Wnt} / \mathrm{B}$-catenin signaling (Kishida et al., 1999; Kan et al., 2020; Ma et al., 2020). The PDZ domain interacts with a conserved KTxxxW motif located immediately after the seventh transmembrane domain of Frizzled receptors (Umbhauer et al., 2000; Wong et al., 2003), and with a wide variety of binding partners that function either as agonists or antagonists of Wnt signaling (Wallingford and Habas, 2005; Sharma et al., 2018). Biochemical and functional analyses suggest that it participates in both $\mathrm{Wnt} / \mathrm{B}$-catenin and Wnt/PCP signaling (Habas et al., 2001; Lee et al., 2015). The DEP domain plays a major role in Dvl membrane recruitment by Frizzled receptors (Axelrod et al., 1998; Rothbächer et al., 2000; Wong et al., 2000; Pan et al., 2004; Park et al., 2005). It functions in the Wnt/PCP pathway either with the PDZ domain to activate Rho/ROCK or by direct interaction with Rac to trigger JNK activation. However, more recent evidence suggests that Dvl dimerization triggered by the $\mathrm{N}$-terminal region of DEP domain is required for Wnt/ß-catenin signaling (Gammons et al., 2016a,b; Paclíková et al., 2017).

The C-terminal region beyond the DEP domain also shows evolutionary conservation but displays unique features among Dvl isofroms. Specifically, Dvl3 contains histidine-single amino acid repeats required for $\mathrm{Wnt} 5 \mathrm{a}$-stimulated activation of nuclear factor of activated $\mathrm{T}$ cells (NF-AT) and possesses prolinerich domains likely involved in the interaction with other Dvl isoforms (Ma et al., 2010; Wang and Malbon, 2012). The extreme 13 amino acids that are conserved in all Dvl isoforms bind to the third intracellular loop of Frizzled receptors and stabilize Frizzled-Dvl interaction in $\mathrm{Wnt} / \mathrm{B}_{\text {-catenin signaling (Tauriello }}$ et al., 2012). Moreover, the last 3 residues represent a type II PDZ-binding (PDZ-B) motif that can occupy the peptide-binding pocket of the PDZ domain, inducing Dvl to adopt a closed conformation and an auto-inhibited state (Lee et al., 2015; Qi et al., 2017). Dvl variants with an opened conformation show efficient membrane recruitment and reduced activity in $\mathrm{Wnt} / \mathrm{B}$ catenin signaling but display increased activity in Wnt/PCP signaling (Qi et al., 2017; Harnoš et al., 2019). The function of Dvl C-terminal region in Wnt signaling is further demonstrated in autosomal-dominant Robinow syndrome caused by de novo frameshift mutations in human DVL1 and DVL3 genes, which delete and replace the $\mathrm{C}$-terminal region after the DEP domain (Bunn et al., 2015; White et al., 2015, 2016; Danyel et al., 2018). In vitro analysis suggests that DVL1 lacking the $\mathrm{C}$-terminal region displays reduced activity in Wnt/ß-catenin signaling (Bunn et al., 2015). These findings suggest an importance of the C-terminus in intra- or inter-molecular interaction, which may be subjected to regulation by other partners to switch pathway specificity. Indeed, recent studies show that casein kinase $1 \varepsilon(\mathrm{CK} 1 \varepsilon)$ and NIMA-related kinase 2 (NEK2) function as scaffold proteins and regulate the dynamics of Dvl conformational changes by phosphorylation of the PDZ domain and modulation of its interaction with the extreme C-terminal tail (Harnoš et al., 2019; Hanáková et al., 2019).

\section{DvI DOSAGE EFFECT ON MORPHOGENETIC MOVEMENTS AND CELL FATE SPECIFICATION DURING DEVELOPMENT IN MICE}

The three $D v l$ genes $(D v l 1, D v l 2$, and $D v l 3)$ in mice are broadly expressed throughout early development. Extensive analyses of mutant phenotypes have uncovered both unique and redundant functions for these genes. Mice deficient in Dvl1 show reduced social interaction and abnormal sensorimotor gating (Lijam et al., 1997). This abnormal behavior is caused by defective $\mathrm{Wnt} /$ ß-catenin signaling that may impair central nervous system functions (Belinson et al., 2016). Mice deficient in Dvl2 exhibit more severe phenotypes, with defective cardiac morphogenesis, somite segmentation, and neural tube closure (Hamblet et al., 2002). Dvl3 functions redundantly with $D v l 1$ and $D v l 2$ in several processes, including cardiac outflow tract, cochlea and neural tube development (Etheridge et al., 2008). These works reveal 


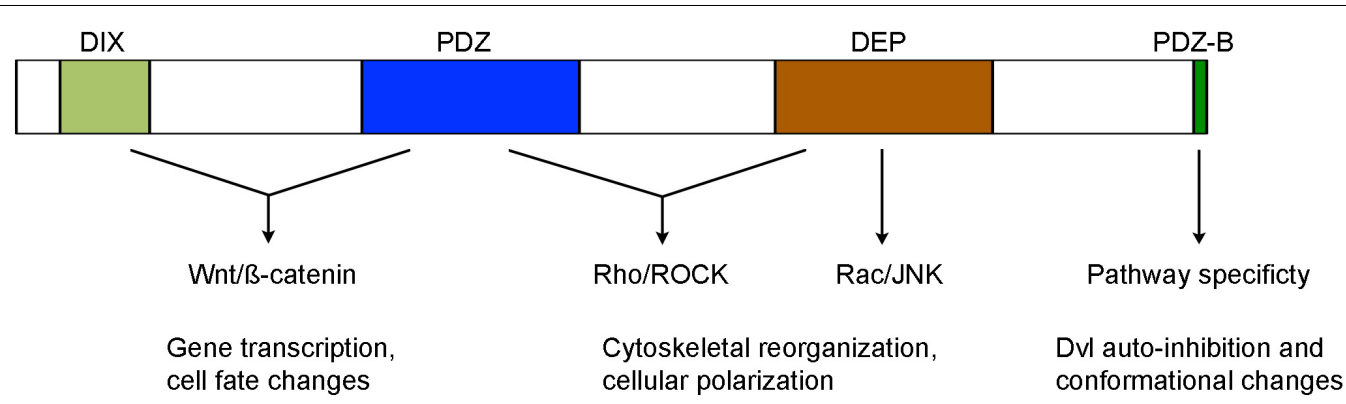

FIGURE 1 | Structure-function relationship of conserved Dvl domains in the activation of Wnt/B-catenin and Wnt/PCP signaling (see text for details).

a sensitivity of Wnt/PCP signaling to $D v l$ dosage because most defective phenotypes in $D v l$ mutants are related to impaired Wnt/PCP signaling, in particular the defective outflow tract morphogenesis (Sinha et al., 2012). Thus, Dvl isoforms are critically required for morphogenetic movements. Particularly, they mediate Wnt/PCP in CE movements during neurulation. Dvl2 plays a predominant role in neural tube closure, but Dvl1 and Dvl3 are also involved in this process (Wang et al., 2006). The functional importance of $\mathrm{Dvl}$ isoforms in neural tube formation has been confirmed by the identification of rare mutations in all three human DVL genes, which disturb normal functions of DVL isoforms in non-canonical Wnt signaling and cause neural tube defects (De Marco et al., 2013; Liu et al., 2020). By comparison, low levels of Dvl expression from a single allele may be sufficient to normally support those developmental processes triggered by the Wnt/ß-catenin pathway (Soares et al., 2005; Wynshaw-Boris, 2012). However, deletion of all six $D v l$ alleles causes absence of mesoderm gene expression and mesoderm formation that are dependent on Wnt/B-catenin signaling (Ngo et al., 2020).

\section{DISTINCT AND REDUNDANT DvI FUNCTIONS DURING XENOPUS DEVELOPMENT}

Dvl function in vertebrates was first studied during Xenopus development. Overexpression of Dvl2 (Xdsh) in the ventral region of early embryos induced the formation of a complete secondary axis reminiscent of activation of maternal Wnt/Bcatenin signaling (Sokol et al., 1995). However, dorsal overexpression of Xdd1, a truncated form of Dvl2 that lacks the PDZ domain and interferes with Wnt/B-catenin signaling triggered by Wnt ligands, did not affect dorsoventral axis formation (Sokol, 1996). Because maternal Wnt/B-catenin signaling is required for dorsal fate specification by activating the transcription of target genes in the Spemann organizer (Carron and Shi, 2016), the absence of an inhibitory effect by Xdd1 implies that Dvl function may be dispensable for the activation of maternal Wnt/ $\beta$-catenin signaling. Consistently, simultaneous depletion of maternally expressed $D v l 2$ and $D v l 3$ from oocytes did not affect the expression of maternal Wnt/ß-catenin target genes and the formation of dorsal axis (Tadjuidje et al., 2011). However, it is possible that low levels of Dvl proteins are still present in the oocytes due to incomplete depletion of maternal $D v l$ mRNA. Thus, the requirement of maternal $D v l$ for dorsal axis formation in Xenopus requires a complete loss-of-function study. Nevertheless, a recent study suggests that activation of maternal Wnt/B-catenin pathway and formation of dorsal axis may be achieved through a Dvl-independent mechanism (Yan et al., 2018). During organogenesis, it seems that Dvl isoforms display less functional redundancy in developmental processes that involve $\mathrm{Wnt} / \mathrm{B}$-catenin signaling, which may be due to their differential expression patterns. For example, Dvl1 and Dvl2 are required for neural crest cell specification and somite segmentation, while Dvl3 maintains gene expression in the myotome (Gray et al., 2009).

Maternal Dvl2 and Dvl3 likely display distinct and redundant functions during $\mathrm{CE}$ movements. In these coordinated processes, lateral cells converge toward the dorsal region to narrow the germ layers, while dorsal midline cells undergo mediolateral intercalation by polarized protrusive behaviors to lengthen the embryo along the anteroposterior axis (Keller and Sutherland, 2020). Previous studies show that Dvl regulates CE movements through Wnt/PCP signaling (Djiane et al., 2000; Tada and Smith, 2000; Habas et al., 2001, 2003; Wallingford and Harland, 2001). Moreover, inhibition of maternal Dvl2 or Dvl3 function suggests that they exhibit a non-redundant but an additive effect on CE movements (Tadjuidje et al., 2011). More recent works reveal that Dvl1, but not Dvl2 or Dvl3, activates the Wnt/ $\mathrm{Ca}^{2+}$ pathway (another branch of the non-canonical pathway) during CE movements (Gentzel et al., 2015), further supporting the distinct functions of Dvl isoforms in morphogenetic movements. As in mice, Dvl function is also required for neural tube closure by regulating $\mathrm{CE}$ movements of the midline and coordinating polarity among epithelial cells (Wallingford and Harland, 2002; Seo et al., 2017). In addition, Dvl2-mediated activation of Rac1 through the DEP domain also controls the protrusive activity of neural crest cells during migration (Kratzer et al., 2020). Because cellular polarization is tightly dependent on the asymmetric activation of Wnt/PCP signaling, both reduced and increased levels of Dvl disrupts asymmetric movements. However, the cellular behaviors are completely different. Increasing the activity of Dvl perturbs cell polarity by randomizing the formation of cellular protrusions, whereas reducing the activity of Dvl prevents cellular protrusions (Wallingford et al., 2000; Cheng et al., 2017). 

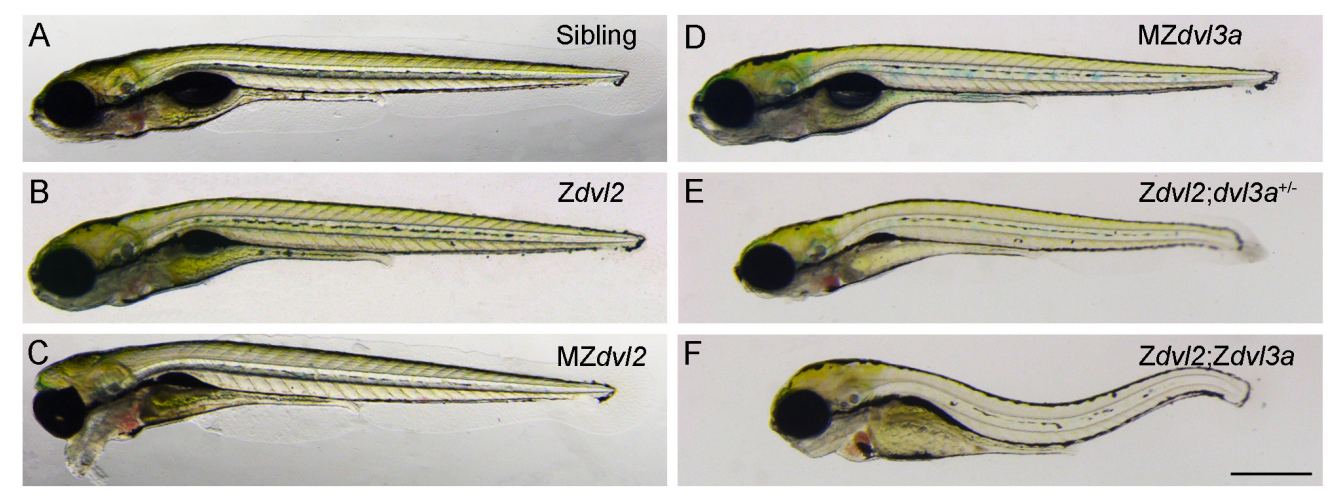

FIGURE 2 | Maternal and zygotic Dvl dosage effect on embryonic axis elongation in zebrafish embryos at 5 days post-fertilization (Xing et al., 2018). (A) Wild-type sibling embryo. (B) Zygotic $d v / 2$ mutant. (C) The "bulldog" facial phenotype of maternal-zygotic dv/2 mutant with cyclopia. (D) Maternal-zygotic $d v / 3 a$ mutant. (E) Triallelic $d v / 2$ and $d v / 3 a$ mutant. (F) Zygotic $d v / 2$ and $d v / 3 a$ double mutant. Scale bar (A-F): $400 \mu \mathrm{m}$.

\section{MATERNAL CONTRIBUTIONS OF DvI PROTEINS TO AXIS PATTERNING AND MORPHOGENETIC PROCESSES DURING ZEBRAFISH DEVELOPMENT}

The zebrafish genome contains five $D v l$ paralogs: $d v l 1 a, d v l 1 b$, $d v l 2, d v l 3 a$, and $d v l 3 b$. In the early embryos, $d v l 2$ and $d v l 3 a$ are maternally expressed and represent about $98 \%$ of the total pool, whereas the transcript levels of the other $D v l$ genes are negligible (Harvey et al., 2013). Knockout of $D v l$ genes reveal both distinct and redundant functions in embryonic axis specification and morphogenetic movements (Xing et al., 2018). Maternal-zygotic mutants for $d v l 1 a, d v l 1 b, d v l 3 a$, and $d v l 3 b$ are phenotypically normal and fertile. In sharp contrast, maternalzygotic $d v l 2$ mutants display strongly impaired CE movements during gastrulation and develop severe craniofacial defects with a "bulldog" facial phenotype, reminiscent of impaired Wnt/PCP signaling in midline structures (Kimmel et al., 2001). Zygotic $d v l 2$ mutant embryos are essentially normal, but only about half of them can survive to adulthood, and all male individuals show absence of courtship behavior. This suggests that there may be defects in central nervous system functions as mice $D v l 1$ mutants (Lijam et al., 1997). The highest level of $d v l 2$ expression during early development may explain at least partly the most severe phenotypes of $d v l 2$ mutants.

The specification of dorsal axis in zebrafish also requires maternal $ß$-catenin signaling to trigger the expression of organizer genes (Kelly et al., 2000; Bellipanni et al., 2006; Fuentes et al., 2020). However, the involvement of upstream regulators has not been conclusively established. Importantly, maternalzygotic $d v l 2$ and $d v l 3 a$ double mutants, which are unresponsive to stimulation by Wnt ligands, show normal specification of dorsal cell fate, suggesting that components of Wnt signaling upstream of $\beta$-catenin may be dispensable for its stabilization. The activation of maternal Wnt/ $/$-catenin signaling independent of Dvl activity is further confirmed in zebrafish huluwa mutants. Maternal depletion of huluwa impairs Wnt/ß-catenin signaling and causes loss of dorso-anterior structures. Mechanistically,
Huluwa protein accumulates in the cell membrane at the dorsal region and functions independently of Wnt ligands and Frizzled receptors to promote tankyrase-mediated degradation of Axin, thereby stabilizing $ß$-catenin (Yan et al., 2018).

Mutational analyses of Dvl functions also reveal a major contribution of maternal Dvl to zygotic events and confirm the importance of Dvl dosage in Wnt/PCP signaling (Figure 2). This dosage effect is particularly reflected by the requirement of Dvl2 and Dvl3a for CE movements. Although Dvl2 plays a predominant role, Dvl3a exerts a strong synergistic effect on the loss of Dvl2 function, and progressive removal of Dvl2 and Dvl3a maternal or zygotic products increasingly aggravates $\mathrm{CE}$ defects and reduces the elongation of anteroposterior axis. Furthermore, zygotic $d v l 2$ and $d v l 3 a$ double mutants only display a shortened body length. However, maternal-zygotic $d v l 2$ and $d v l 3 a$ double mutants show most strongly impaired $\mathrm{CE}$ movements and completely lack axis extension. They also develop severe trunk and posterior deficiencies associated with down-regulation of zygotic Wnt/ß-catenin target genes (Xing et al., 2018). Because zygotic Wnt/B-catenin signaling has an opposite effect with respect to maternal Wnt/B-catenin signaling and functions to specify the posterior region (Carron and Shi, 2016), these findings highlight the importance of maternal Dvl in setting up zygotic morphogenetic and patterning processes. They support the view that maternally expressed gene products perform essential functions after zygotic genome activation (Marlow, 2020; Solnica-Krezel, 2020). Thus, both maternal and zygotic Dvl dosages are important for proper cell movements and embryonic axis patterning that occur during gastrulation.

\section{PERSPECTIVES}

Dvl conserved domains in Wnt pathways have attracted much attention. Although the function of DIX, PDZ, and DEP domains is relatively understood, how they cooperate to switch pathway specificity remains elusive. Detailed analysis of other conserved domains or isoform-specific regions, such as the basic region 
preceding the PDZ domain, the proline-rich region and histidinesingle amino acid repeats in the $\mathrm{C}$-terminal region beyond the DEP domain, and the extreme C-terminus, may provide insights into Dvl-mediated signal transduction. Because Dvl post-translational modifications, in particular phosphorylation and ubiquitination, and Dvl interaction partners are important for subcellular localizations and specific functions of Dvl proteins (Sharma et al., 2018; Harrison et al., 2020), it is of interest to understand how these modulate Dvl activity and dictate signaling outcomes in key developmental processes. Indeed, dysregulation of Dvl phosphorylation impairs both Wnt/ßcatenin and Wnt/PCP signaling during zebrafish and Xenopus embryogenesis (Shimizu et al., 2014; Rauschenberger et al., 2017). The specificity of Dvl isoforms also merits investigations because tissue-specific expression patterns and differential biochemical properties may contribute to their particular functions. Another intriguing question is the sensibility of Wnt/PCP signaling, but not Wnt/B-catenin signaling, to Dvl dosage, which is observed in all vertebrates. It suggests that Wnt/PCP-dependent developmental processes critically require Dvl function to activate downstream effectors. Consequently, moderate diminution of Dvl dosage could significantly affect

\section{REFERENCES}

Axelrod, J. D., Miller, J. R., Shulman, J. M., Moon, R. T., and Perrimon, N. (1998). Differential recruitment of Dishevelled provides signaling specificity in the planar cell polarity and Wingless signaling pathways. Genes Dev. 12, 2610-2622. doi: 10.1101/gad.12.16.2610

Belinson, H., Nakatani, J., Babineau, B. A., Birnbaum, R. Y., Ellegood, J., Bershteyn, M., et al. (2016). Prenatal $\beta$-catenin/Brn2/Tbr2 transcriptional cascade regulates adult social and stereotypic behaviors. Mol. Psychiatry 21, 1417-1433. doi: 10. 1038/mp.2015.207

Bellipanni, G., Varga, M., Maegawa, S., Imai, Y., Kelly, C., Myers, A. P., et al. (2006). Essential and opposing roles of zebrafish beta-catenins in the formation of dorsal axial structures and neurectoderm. Development 133, 1299-1309. doi: 10.1242/dev.02295

Boutros, M., and Mlodzik, M. (1999). Dishevelled: at the crossroads of divergent intracellular signaling pathways. Mech. Dev. 83, 27-37. doi: 10.1016/s09254773(99)00046-5

Bunn, K. J., Daniel, P., Rösken, H. S., O’Neill, A. C., Cameron-Christie, S. R., Morgan, T., et al. (2015). Mutations in DVL1 cause an osteosclerotic form of robinow syndrome. Am. J. Hum. Genet. 96, 623-630. doi: 10.1016/j.ajhg.2015. 02.010

Butler, M. T., and Wallingford, J. B. (2017). Planar cell polarity in development and disease. Nat. Rev. Mol. Cell Biol. 18, 375-388. doi: 10.1038/nrm.2017.11

Carron, C., and Shi, D. L. (2016). Specification of anteroposterior axis by combinatorial signaling during Xenopus development. Wiley Interdiscip. Rev. Dev. Biol. 5, 150-168. doi: 10.1002/wdev.217

Cheng, X. N., Shao, M., Li, J. T., Wang, Y. F., Qi, J., Xu, Z. G., et al. (2017). Leucine repeat adaptor protein 1 interacts with Dishevelled to regulate gastrulation cell movements in zebrafish. Nat. Commun. 8:1353. doi: 10.1038/s41467-01701552-x

Clevers, H., and Nusse, R. (2012). Wnt/ $\beta$-catenin signaling and disease. Cell 149, 1192-1205. doi: 10.1016/j.cell.2012.05.012

Danyel, M., Kortüm, F., Dathe, K., Kutsche, K., and Horn, D. (2018). Autosomal dominant Robinow syndrome associated with a novel DVL3 splice mutation. Am. J. Med. Genet. A 176, 992-996. doi: 10.1002/ajmg.a.38635

De Marco, P., Merello, E., Consales, A., Piatelli, G., Cama, A., Kibar, Z., et al. (2013). Genetic analysis of disheveled 2 and disheveled 3 in human neural tube defects. J. Mol. Neurosci. 49, 582-588. doi: 10.1007/s12031-012-9871-9 polarized cellular behaviors and cell polarity. By comparison, B-catenin may be stabilized independently of upstream Wnt signaling components, and target genes of $\mathrm{Wnt} / \mathrm{B}$-catenin signaling may be regulated by other factors, at least during dorsal fate specification in zebrafish and Xenopus (Li et al., 2015; Yan et al., 2018). Thus, tissue morphogenesis regulated by Wnt/PCP signaling is more sensitive to Dvl dysfunction, as a result, many human congenital disorders, such as neural tube defects and Robinow syndrome, are associated with mutations in DVL genes.

\section{AUTHOR CONTRIBUTIONS}

D-LS performed the literature analysis, prepared the figures, and wrote the manuscript.

\section{FUNDING}

This work was supported by the Centre National de la Recherche Scientifique (CNRS) and the Sorbonne University.

Djiane, A., Riou, J., Umbhauer, M., Boucaut, J., and Shi, D. L. (2000). Role of frizzled 7 in the regulation of convergent extension movements during gastrulation in Xenopus laevis. Development 127, 3091-3100.

Etheridge, S. L., Ray, S., Li, S., Hamblet, N. S., Lijam, N., Tsang, M., et al. (2008). Murine dishevelled 3 functions in redundant pathways with dishevelled 1 and 2 in normal cardiac outflow tract, cochlea, and neural tube development. PLoS Genet. 4:e1000259. doi: 10.1371/journal.pgen.100 0259

Fuentes, R., Tajer, B., Kobayashi, M., Pelliccia, J. L., Langdon, Y., Abrams, E. W., et al. (2020). The maternal coordinate system: molecular-genetics of embryonic axis formation and patterning in the zebrafish. Curr. Top. Dev. Biol. 140, 341-389. doi: 10.1016/bs.ctdb.2020.05.002

Gammons, M. V., Renko, M., Johnson, C. M., Rutherford, T. J., and Bienz, M. (2016a). Wnt signalosome assembly by DEP domain swapping of dishevelled. Mol. Cell 64, 92-104. doi: 10.1016/j.molcel.2016.08.026

Gammons, M. V., Rutherford, T. J., Steinhart, Z., Angers, S., and Bienz, M. (2016b). Essential role of the Dishevelled DEP domain in a Wnt-dependent humancell-based complementation assay. J. Cell Sci. 129, 3892-3902. doi: 10.1242/jcs. 195685

Gao, C., and Chen, Y. G. (2010). Dishevelled: the hub of Wnt signaling. Cell. Signal. 22, 717-727. doi: 10.1016/j.cellsig.2009.11.021

Gentzel, M., and Schambony, A. (2017). Dishevelled paralogs in vertebrate development: redundant or distinct? Front. Cell Dev. Biol. 5:59. doi: 10.3389/ fcell.2017.00059

Gentzel, M., Schille, C., Rauschenberger, V., and Schambony, A. (2015). Distinct functionality of dishevelled isoforms on $\mathrm{Ca} 2+/$ calmodulin-dependent protein kinase 2 (CamKII) in Xenopus gastrulation. Mol. Biol. Cell 26, 966-977. doi: 10.1091/mbc.E14-06-1089

Gray, R. S., Bayly, R. D., Green, S. A., Agarwala, S., Lowe, C. J., and Wallingford, J. B. (2009). Diversification of the expression patterns and developmental functions of the dishevelled gene family during chordate evolution. Dev. Dyn. 238, 2044-2057. doi: 10.1002/dvdy.22028

Green, J., Nusse, R., and van Amerongen, R. (2014). The role of Ryk and Ror receptor tyrosine kinases in Wnt signal transduction. Cold Spring Harb Perspect. Biol. 6:a009175. doi: 10.1101/cshperspect.a009175

Habas, R., Dawid, I. B., and He, X. (2003). Coactivation of Rac and Rho by Wnt/Frizzled signaling is required for vertebrate gastrulation. Genes Dev. 17, 295-309. doi: 10.1101/gad.1022203 
Habas, R., Kato, Y., and He, X. (2001). Wnt/Frizzled activation of Rho regulates vertebrate gastrulation and requires a novel Formin homology protein Daam1. Cell 107, 843-854. doi: 10.1016/s0092-8674(01)00614-6

Hamblet, N. S., Lijam, N., Ruiz-Lozano, P., Wang, J., Yang, Y., Luo, Z., et al. (2002). Dishevelled 2 is essential for cardiac outflow tract development, somite segmentation and neural tube closure. Development 129, 5827-5838. doi: 10. 1242/dev.00164

Hanáková, K., Bernatík, O., Kravec, M., Micka, M., Kumar, J., Harnoš, J., et al. (2019). Comparative phosphorylation map of Dishevelled 3 links phosphosignatures to biological outputs. Cell Commun. Signal. 17:170. doi: 10.1186/ s12964-019-0470-z

Harnoš, J., Cañizal, M. C. A., Jurásek, M., Kumar, J., Holler, C., Schambony, A., et al. (2019). Dishevelled-3 conformation dynamics analyzed by FRET-based biosensors reveals a key role of casein kinase 1. Nat. Commun. 10:1804. doi: 10.1038/s41467-019-09651-7

Harrison, C., Shao, H., Strutt, H., and Strutt, D. (2020). Molecular mechanisms mediating asymmetric subcellular localisation of the core planar polarity pathway proteins. Biochem. Soc. Trans. 48, 1297-1308. doi: 10.1042/ BST20190404

Harvey, S. A., Sealy, I., Kettleborough, R., Fenyes, F., White, R., Stemple, D., et al. (2013). Identification of the zebrafish maternal and paternal transcriptomes. Development 140, 2703-2710. doi: 10.1242/dev.095091

Humphries, A. C., and Mlodzik, M. (2018). From instruction to output: Wnt/PCP signaling in development and cancer. Curr. Opin. Cell Biol. 51, 110-116. doi: 10.1016/j.ceb.2017.12.005

Jiang, X., and Cong, F. (2016). Novel regulation of Wnt signaling at the proximal membrane level. Trends Biochem. Sci. 41, 773-783. doi: 10.1016/j.tibs.2016.06. 003

Kan, W., Enos, M. D., Korkmazhan, E., Muennich, S., Chen, D. H., Gammons, M. V., et al. (2020). Limited dishevelled/Axin oligomerization determines efficiency of Wnt/ $\beta$-catenin signal transduction. eLife 9:e55015. doi: 10.7554/ eLife. 55015

Keller, R., and Sutherland, A. (2020). Convergent extension in the amphibian, Xenopus laevis. Curr. Top. Dev. Biol. 136, 271-317. doi: 10.1016/bs.ctdb.2019. 11.013

Kelly, C., Chin, A. J., Leatherman, J. L., Kozlowski, D. J., and Weinberg, E. S. (2000). Maternally controlled (beta)-catenin-mediated signaling is required for organizer formation in the zebrafish. Development 127, 3899-3911.

Kimmel, C. B., Miller, C. T., and Moens, C. B. (2001). Specification and morphogenesis of the zebrafish larval head skeleton. Dev. Biol. 233, 239-257. doi: 10.1006/dbio.2001.0201

Kishida, S., Yamamoto, H., Hino, S., Ikeda, S., Kishida, M., and Kikuchi, A. (1999). DIX domains of Dvl and axin are necessary for protein interactions and their ability to regulate beta-catenin stability. Mol. Cell. Biol. 19, 4414-4422. doi: $10.1128 / \mathrm{mcb} \cdot 19.6 .4414$

Kratzer, M. C., Becker, S. F. S., Grund, A., Merks, A., Harnoš, J., Bryja, V., et al. (2020). The Rho guanine nucleotide exchange factor Trio is required for neural crest cell migration and interacts with Dishevelled. Development 147:dev186338. doi: 10.1242/dev.186338

Lee, H. J., Shi, D. L., and Zheng, J. J. (2015). Conformational change of Dishevelled plays a key regulatory role in the Wnt signaling pathways. eLife 4:e08142. doi: 10.7554/eLife.08142

Lehoczky, J. A., and Tabin, C. J. (2018). Rethinking WNT signalling. Nature 557, 495-496. doi: 10.1038/d41586-018-04820-y

Li, H. Y., El Yakoubi, W., and Shi, D. L. (2015). Direct regulation of siamois by VegT is required for axis formation in Xenopus embryo. Int. J. Dev. Biol. 59, 443-451. doi: 10.1387/ijdb.150040ds

Lijam, N., Paylor, R., McDonald, M. P., Crawley, J. N., Deng, C. X., Herrup, K., et al. (1997). Social interaction and sensorimotor gating abnormalities in mice lacking Dvl1. Cell 90, 895-905. doi: 10.1016/s0092-8674(00)80354-2

Liu, L., Liu, W., Shi, Y., Gao, Y., Lei, Y., Finnel, R., et al. (2020). DVL mutations identified from human neural tube defects and Dandy-Walker malformation obstruct the Wnt signaling pathway. J. Genet. Genom. (in press). doi: 10.1016/j. jgg.2020.06.003

Ma, L., Wang, Y., Malbon, C. C., and Wang, H. Y. (2010). Dishevelled-3 C-terminal His single amino acid repeats are obligate for Wnt5a activation of noncanonical signaling. J. Mol. Signal. 5:19. doi: 10.1186/1750-2187-5-19
Ma, W., Chen, M., Kang, H., Steinhart, Z., Angers, S., He, X., et al. (2020). Singlemolecule dynamics of Dishevelled at the plasma membrane and Wnt pathway activation. Proc. Natl. Acad. Sci. U.S.A. 117, 16690-16701. doi: 10.1073/pnas. 1910547117

Marlow, F. L. (2020). Setting up for gastrulation in zebrafish. Curr. Top. Dev. Biol. 136, 33-83. doi: 10.1016/bs.ctdb.2019.08.002

Mlodzik, M. (2016). The Dishevelled protein family: still rather a mystery after over 20 years of molecular studies. Curr. Top. Dev. Biol. 117, 75-91. doi: 10.1016/bs. ctdb.2015.11.027

Ngo, J., Hashimoto, M., Hamada, H., and Wynshaw-Boris, A. (2020). Deletion of the dishevelled family of genes disrupts anterior-posterior axis specification and selectively prevents mesoderm differentiation. Dev. Biol. 464, 161-175. doi: 10.1016/j.ydbio.2020.05.010

Niehrs, C. (2012). The complex world of WNT receptor signalling. Nat. Rev. Mol. Cell Biol. 13, 767-779. doi: 10.1038/nrm3470

Paclíková, P., Bernatík, O., Radaszkiewicz, T. W., and Bryja, V. (2017). The $\mathrm{N}$-terminal part of the Dishevelled DEP domain is required for Wnt/ $/$-Catenin signaling in mammalian cells. Mol. Cell. Biol. 37:e00145-17. doi: 10.1128/MCB. 00145- 17

Pan, W. J., Pang, S. Z., Huang, T., Guo, H. Y., Wu, D., and Li, L. (2004). Characterization of function of three domains in dishevelled-1: DEP domain is responsible for membrane translocation of dishevelled-1. Cell Res. 14, 324-330. doi: 10.1038/sj.cr.7290232

Park, T. J., Gray, R. S., Sato, A., Habas, R., and Wallingford, J. B. (2005). Subcellular localization and signaling properties of dishevelled in developing vertebrate embryos. Curr. Biol. 15, 1039-1044. doi: 10.1016/j.cub.2005.04.062

Qi, J., Lee, H. J., Saquet, A., Cheng, X. N., Shao, M., Zheng, J. J., et al. (2017). Autoinhibition of Dishevelled protein regulated by its extreme $\mathrm{C}$ terminus plays a distinct role in Wnt/ $\beta$-catenin and Wnt/planar cell polarity (PCP) signaling pathways. J. Biol. Chem. 292, 5898-5908. doi: 10.1074/jbc.M116.772509

Rauschenberger, V., Bernkopf, D. B., Krenn, S., Jalal, K., Heller, J., Behrens, J., et al. (2017). The phosphatase Pgam5 antagonizes Wnt/ $\beta$-Catenin signaling in embryonic anterior-posterior axis patterning. Development 144, 2234-2247. doi: $10.1242 /$ dev.144477

Rothbächer, U., Laurent, M. N., Deardorff, M. A., Klein, P. S., Cho, K. W., and Fraser, S. E. (2000). Dishevelled phosphorylation, subcellular localization and multimerization regulate its role in early embryogenesis. EMBO J. 19, 1010-1022. doi: 10.1093/emboj/19.5.1010

Seo, H. S., Habas, R., Chang, C., and Wang, J. (2017). Bimodal regulation of Dishevelled function by Vangl2 during morphogenesis. Hum. Mol. Genet. 26, 2053-2061. doi: 10.1093/hmg/ddx095

Sharma, M., Castro-Piedras, I., Simmons, G. E. Jr., and Pruitt, K. (2018). Dishevelled: a masterful conductor of complex Wnt signals. Cell. Signal. 47, 52-64. doi: 10.1016/j.cellsig.2018.03.004

Shimizu, N., Ishitani, S., Sato, A., Shibuya, H., and Ishitani, T. (2014). Hipk2 and PP1c cooperate to maintain Dvl protein levels required for Wnt signal transduction. Cell Rep. 8, 1391-1404. doi: 10.1016/j.celrep.2014.07.040

Sinha, T., Wang, B., Evans, S., Wynshaw-Boris, A., and Wang, J. (2012). Disheveled mediated planar cell polarity signaling is required in the second heart field lineage for outflow tract morphogenesis. Dev. Biol. 370, 135-144. doi: 10.1016/ j.ydbio.2012.07.023

Soares, M. L., Haraguchi, S., Torres-Padilla, M. E., Kalmar, T., Carpenter, L., Bell, G., et al. (2005). Functional studies of signaling pathways in peri-implantation development of the mouse embryo by RNAi. BMC Dev. Biol. 5:28. doi: 10.1186/ 1471-213X-5-28

Sokol, S. Y. (1996). Analysis of Dishevelled signalling pathways during Xenopus development. Curr. Biol. 6, 1456-1467. doi: 10.1016/s0960-9822(96)00750-6

Sokol, S. Y., Klingensmith, J., Perrimon, N., and Itoh, K. (1995). Dorsalizing and neuralizing properties of Xdsh, a maternally expressed Xenopus homolog of dishevelled. Development 121, 1637-1647.

Solnica-Krezel, L. (2020). Maternal contributions to gastrulation in zebrafish. Curr. Top. Dev. Biol. 140, 391-427. doi: 10.1016/bs.ctdb.2020.05.001

Steinhart, Z., and Angers, S. (2018). Wnt signaling in development and tissue homeostasis. Development 145:dev146589. doi: 10.1242/dev.146589

Stricker, S., Rauschenberger, V., and Schambony, A. (2017). ROR-family receptor tyrosine kinases. Curr. Top. Dev. Biol. 123, 105-142. doi: 10.1016/bs.ctdb.2016. 09.003 
Tada, M., and Smith, J. C. (2000). Xwnt11 is a target of Xenopus brachyury: regulation of gastrulation movements via Dishevelled, but not through the canonical Wnt pathway. Development 127, 2227-2238.

Tadjuidje, E., Cha, S. W., Louza, M., Wylie, C., and Heasman, J. (2011). The functions of maternal Dishevelled 2 and 3 in the early Xenopus embryo. Dev. Dyn. 240, 1727-1736. doi: 10.1002/dvdy.22671

Tauriello, D. V., Jordens, I., Kirchner, K., Slootstra, J. W., Kruitwagen, T., Bouwman, B. A., et al. (2012). Wnt/ $\beta$-catenin signaling requires interaction of the Dishevelled DEP domain and $\mathrm{C}$ terminus with a discontinuous motif in Frizzled. Proc. Natl. Acad. Sci. U.S.A. 109, E812-E820. doi: 10.1073/pnas. 1114802109

Umbhauer, M., Djiane, A., Goisset, C., Penzo-Méndez, A., Riou, J. F., Boucaut, J. C., et al. (2000). The C-terminal cytoplasmic Lys-Thr-X-X-X-Trp motif in frizzled receptors mediates Wnt/beta-catenin signalling. EMBO J. 19, 4944-4954. doi: 10.1093/emboj/19.18.4944

Wallingford, J. B., and Habas, R. (2005). The developmental biology of Dishevelled: an enigmatic protein governing cell fate and cell polarity. Development 132, 4421-4436. doi: 10.1242/dev.02068

Wallingford, J. B., and Harland, R. M. (2001). Xenopus Dishevelled signaling regulates both neural and mesodermal convergent extension: parallel forces elongating the body axis. Development 128, 2581-2592.

Wallingford, J. B., and Harland, R. M. (2002). Neural tube closure requires Dishevelled-dependent convergent extension of the midline. Development 129 , 5815-5825. doi: 10.1242/dev.00123

Wallingford, J. B., Rowning, B. A., Vogeli, K. M., Rothbächer, U., Fraser, S. E., and Harland, R. M. (2000). Dishevelled controls cell polarity during Xenopus gastrulation. Nature 405, 81-85. doi: 10.1038/35011077

Wang, H. Y., and Malbon, C. C. (2012). Dishevelled C-terminus: prolyl and histidinyl motifs. Acta Physiol. 204, 65-73. doi: 10.1111/j.1748-1716.2011. 02291.x

Wang, J., Hamblet, N. S., Mark, S., Dickinson, M. E., Brinkman, B. C., Segil, N., et al. (2006). Dishevelled genes mediate a conserved mammalian PCP pathway to regulate convergent extension during neurulation. Development 133, 1767-1778. doi: 10.1242/dev.02347

White, J. J., Mazzeu, J. F., Coban-Akdemir, Z., Bayram, Y., Bahrambeigi, V., Hoischen, A., et al. (2015). DVL1 frameshift mutations clustering in the penultimate exon cause autosomal-dominant Robinow syndrome. Am. J. Hum. Genet. 96, 612-622. doi: 10.1016/j.ajhg.2015.02.015

White, J. J., Mazzeu, J. F., Hoischen, A., Bayram, Y., Withers, M., Gezdirici, A., et al. (2016). DVL3 alleles resulting in a -1 frameshift of the last exon mediate autosomal-dominant Robinow syndrome. Am. J. Hum. Genet. 98, 553-561. doi: 10.1016/j.ajhg.2016.01.005

Wiese, K. E., Nusse, R., and van Amerongen, R. (2018). Wnt signalling: conquering complexity. Development 145:dev165902. doi: 10.1242/dev.165902

Wong, H. C., Bourdelas, A., Krauss, A., Lee, H. J., Shao, Y., Wu, D., et al. (2003). Direct binding of the PDZ domain of Dishevelled to a conserved internal sequence in the C-terminal region of Frizzled. Mol. Cell 12, 1251-1260. doi: 10.1016/s1097-2765(03)00427-1

Wong, H. C., Mao, J., Nguyen, J. T., Srinivas, S., Zhang, W., Liu, B., et al. (2000). Structural basis of the recognition of the dishevelled DEP domain in the Wnt signaling pathway. Nat. Struct. Biol. 7, 1178-1184. doi: 10.1038/82047

Wynshaw-Boris, A. (2012). Dishevelled: in vivo roles of a multifunctional gene family during development. Curr. Top. Dev. Biol. 101, 213-235. doi: 10.1016/ B978-0-12-394592-1.00007-7

Xing, Y. Y., Cheng, X. N., Li, Y. L., Zhang, C., Saquet, A., Liu, Y. Y., et al. (2018). Mutational analysis of dishevelled genes in zebrafish reveals distinct functions in embryonic patterning and gastrulation cell movements. PLoS Genet. 14:e1007551. doi: 10.1371/journal.pgen.1007551

Yan, L., Chen, J., Zhu, X., Sun, J., Wu, X., Shen, W., et al. (2018). Maternal Huluwa dictates the embryonic body axis through $\beta$-catenin in vertebrates. Science 362:eaat1045. doi: 10.1126/science.aat1045

Conflict of Interest: The author declares that the research was conducted in the absence of any commercial or financial relationships that could be construed as a potential conflict of interest.

Copyright (c) 2020 Shi. This is an open-access article distributed under the terms of the Creative Commons Attribution License (CC BY). The use, distribution or reproduction in other forums is permitted, provided the original author(s) and the copyright owner(s) are credited and that the original publication in this journal is cited, in accordance with accepted academic practice. No use, distribution or reproduction is permitted which does not comply with these terms. 